\title{
I ndigenously developed monoclonal antibody specific for human blood group B
}

\author{
Ajay V Abhyankar, Nimesh Gandhi, Priyanka Panchal, Yegneshwar I yer, Madhu Patel \\ R\&D, Span diagnostics Ltd., Plot no 334-336-338, Road No.3, GIDC, Sachin, Surat, Gujarat, India. \\ Correspondence: Ajay Abhyankar. Address: Span diagnostics Ltd., Plot no 334-336-338, Road No. 3, GIDC, Sachin, \\ Surat, Gujarat, India. Telephone: 91-0261-2397-712. E-mail: abhyankarjay@gmail.com
}

Received: March 26, 2012

DOI : $10.5430 /$ jhm.v2n2p18

Accepted: April 26, 2012

URL: http://dx.doi.org/10.5430/jhm.v2n2p18

Published: June 1, 2012

\author{
8
}

\section{Abstract}

Objective: The quality blood grouping reagents is clearly an important factor for blood transfusion and diagnostics and many international standard Anti-B reagents are available for blood grouping in India and there is a need of indigenously developed, cost effective potent Anti-B secreting monoclonal antibody which can be used as a standard blood grouping reagent. To develop indigenous, cost effective standard Anti-B reagent which can be used in the scale up system to ensures constant supply which will ultimately be cost-effective if produced in-house.

Method: Murine anti-B monoclonal antibodies have been produced by hybridoma fusion with specificity for human blood group B following the immunization of BALB/c mice with group B cells.

Results: Three hybridoma clones were developed with specificity to human B blood group. Out of three hybridoma clones two of them, show potent titer, avidity, and sensitivity to be used as blood typing reagent. One clone, 3D5D7G2 reacted well in screening tests with an avidity of $<4$ seconds with B cell.

Conclusion: This IgM antibody reacted with 100\% accuracy when tested with more than 2500 samples of A, B, O blood groups and satisfies all the laid down criteria under WHO guidelines to be labeled as an Anti-B reagent. The suitability of these antibodies as blood grouping reagents is discussed.

\section{Key words}

Anti-B, Monoclonal antibody, Potency, Specificity, Avidity

\section{I ntroduction}

The discovery of A, B, O blood groups by Landsteiner in $1901^{[1]}$, found in most secretions and tissues, has gained great importance in blood transfusion service in typing of blood donors and recipients during transfusions, organ transplants and to ensure safe blood transfusion. The A, B, O antigen is present on the surface of erythrocytes and the use of monoclonal antibodies (MAbs) as typing reagents is limited by their capacity to react with a single epitope. In India A, B, O blood typing reagents are generally procured from western sources and there are no indigenously developed clone, representing the epitopes of the Asian population that can be used as a typing reagent. Hence the aim of this exercise is to generate an indigenous clone, satisfying all the laid down criteria to be labeled as a potent typing reagent.

With the advent of hybridoma technology ${ }^{[2]}$, murine monoclonal antibodies unlike polyclonal antisera once generated indigenously will not only be cost effective but also provides the same antibodies without any batch variation over a long 
period of time. Indigenous development of monoclonal antibody being cost effective has progressed rapidly for the production of a low grade diagnostic reagent ${ }^{[3-5]}$. Monoclonal antibody with anti-B specificity and with potential as a blood grouping reagent was produced following the immunization protocol employed which differs from previously reported in dosage and in the timings of the inoculations of a mouse with group B red cells ${ }^{[6]}$. There had been other reports of monoclonal antibodies with blood group B specificity ${ }^{[7-10]}$ with each of the group employing a different immunization protocol.

One of the antibody clones 3D5D7G2 satisfies the laid down criteria of potency, avidity and specificity to be used as a promising blood grouping reagent.

\section{Material and methods}

\section{I mmunization schedule}

Four to six weeks old female BALB/C mice were immunized intraperitoneally with modified protocol with $10 \%$ suspension of group B red cells in phosphate buffered saline obtained from healthy individual at an interval of 0, 10, 20 days with a final booster on 30th day three days before fusion ${ }^{[6]}$. On day 15 , mice were test bled through the retro orbital plexus and the titer of serum antibodies was determined by of tube hemagglutination technique ${ }^{[4-7]}$.

\section{Hybridoma production \& cloning}

Spleen cells from immunized mice were prepared after the final dose of the booster and mixed with 1:5 ratio of Sp2/0-Ag14 mouse myeloma cells in presence of 50\% polyethylene glycol 4000 (Merck) using the procedure described by Köhler and Milstein ${ }^{[2]}$. After the fusion, the cells were resuspended in Hypoxanthine Aminopterine Thymidine (HAT) made with Iscove's modified Dulbecco's medium, supplemented with $20 \%$ fetal bovine serum (FBS) (Gibco), $100 \mathrm{uL} / \mathrm{mL}$ of penicillin, $100 \mathrm{pg} / \mathrm{mL}$ streptomycin, $2 \mathrm{mM}$ L-glutamine, $10-8 \mathrm{M}$ hypoxanthine, $4 \times 10^{-5} \mathrm{M}$ aminopterin, and $1.6 \times 10^{-3} \mathrm{M}$ thymidine (All reagents from Sigma). $200 \mu \mathrm{L}$ were seeded on 96 -well tissue culture plates along with mouse macrophage feeder layer (Nunc, DK 4000 Roskilde, Denmark). The plates were incubated at $37^{\circ} \mathrm{C}$ in moisturized atmosphere with $5 \%$ $\mathrm{CO}_{2}$ in air. Seven days after fusion, wells were replenished with HT medium and after 3-5 days supernatants from the wells exhibiting hybridoma growth were screened by hemagglutination for anti-B antibodies using A, B and O red cells. All B red cell specific positive clones were expanded to 24-well plates and the cells were frozen under liquid nitrogen in a medium containing 90\% FBS and 10\% dimethylsulfoxide (DMSO, Sigma). Hybrid clones of interest were selected on the basis of their specificity, titer, and avidity by the hemagglutination reaction and re-cloned twice by the limiting dilution technique. Immunoglobulin class was determined by ELISA using class-specific reagents (Sigma). The culture supernatants were centrifuged and stored containing $0.1 \%$ Na-azide and kept at $4{ }^{\circ} \mathrm{C}$. The clones were cryopreserved in liquid nitrogen for future reference.

\section{Hemagglutination assays}

Anti-B Blood Grouping Reagent (Span Diagnostics Ltd., India) used as a standard and control reagent throughout this work. Red cells were washed three times in $0.15 \mathrm{M}$ sodium chloride; suspensions were made in $0.15 \mathrm{M}$ sodium chloride from the washed packed cells. The culture supernatants were tested with random A, B, O and AB human adult red cells. To rule out the presence of cross reactivity and to check the titer, avidity and specificity, culture supernatants were tested with $\mathrm{A}, \mathrm{B}$ and $\mathrm{O}$ red cells at $37^{\circ} \mathrm{C}, 4^{\circ} \mathrm{C}$, and room temperature by saline and $2 \%$ BSA in PBS as per the standard procedures ${ }^{[11]}$.

The inhibitory capacity of the B substance (Purified from meconium) by the agglutination produced by MAbs of interest were performed according to the classical method with doubling dilutions of B-substance. The agglutinating system was composed of red blood cells $(50 \mu \mathrm{L})$ and $50 \mu \mathrm{L}$ of monoclonal anti-B diluted at $1 / 50$. Different saliva from ABH secretor or non-secretor subjects was used. 


\section{ELISA to measure concentration of anti-B antibodies}

Polystyrene micro titer plates (NUNC) were coated with $100 \mu \mathrm{L} /$ well of $5 \mathrm{ug} / \mathrm{mL}$ of anti-human IgM in $0.1 \mathrm{M}$ bicarbonate buffer, $\mathrm{pH}$ 9.6, overnight at $4^{\circ} \mathrm{C}$. The next day plates were washed 3 times with $0.01 \mathrm{M}$ phosphate buffer saline (PBS), $\mathrm{pH}$ 7.3 containing $0.05 \%$ Tween-20 (Sigma) and non-specific binding site were blocked for 2 hours with 2\% BSA in PBS at $37^{\circ} \mathrm{C}$. After 2 hours, the plates were washed with PBS $+0.05 \%$ Tween-20 and Anti-B culture supernatant (3D5D7G2) and references were added. After an hour of incubation at $37^{\circ} \mathrm{C}$, the plates were washed 3 times with PBS $+0.05 \%$ Tween-20; than $100 \mu \mathrm{L}$ of Goat Anti-mouse IgM HRP (Sigma), diluted 1:2000 in 0.2\% BSA in PBS was added, as the secondary antibody. After one hour of incubation at $37^{\circ} \mathrm{C}$, the plates were washed 3 times with PBS $+0.05 \%$ Tween-20 and then $100 \mu \mathrm{L}$ of TMB substrate were added, and the reaction was stopped after 5 minutes with 2N H2SO4. Optical density was read at 450nm in ELISA reader. To measure the Immunoglobulin concentration of culture supernatant of Anti-B antibody, a logarithmic curve $\mathrm{Y}=\mathrm{A}+\mathrm{B} \log \mathrm{X}$ is fitted to calculate the concentration, in between the OD Vs. the dilutions.

\section{Results and discussion}

Out of the 386 wells seeded only 128 yielded hybrids of which twenty eight wells were positive for agglutination tests with human ABO red blood cells in 96-well U-bottomed plates. Out of the twenty eight wells, three of the hybridomas secreted specific antibodies that agglutinated only with B group red blood cells. To get enough supernatant volume for avidity and intensity tests, the positive clones from the first selection were expanded to 24-well plates and sub-cloned twice by limiting dilution.

From this study, only one antibody (3D5D7G2) specific for B red blood cells showed enough potential characteristics to be used as typing reagent for B blood group. The properties of this antibody are summarized in Table- 1 \& 2 with respect to Avidity, potency \& Specificity.

Table 1. Avidity, intensity and titer of the 3D5D7G2 monoclonal antibody by tube agglutination assay

\begin{tabular}{llllll}
\hline Red Cells & No. of samples & Avidity (in seconds) & Intensity & Titer \\
\hline & & Whole blood & $10 \%$ cell & & \\
B & 880 & 3.1 & 3.2 & $4+$ & 512 \\
AB & 15 & 3.5 & 3.9 & $2+$ & 128 \\
A1B & 15 & 3.4 & 3.7 & $2+$ & 64 \\
A2B & 14 & 3.5 & 3.8 & $2+$ & 64 \\
\hline
\end{tabular}

A drop of culture supernatant was pipette on to a clean glass slide and to this was added one drop of a whole blood and $10 \%$ washed cell suspension. The time taken (In seconds) for visible agglutination to be observed was determined using a stop-watch and recorded as the avidity of the reagent. The avidity test has proved useful in the evaluation of both human sera and monoclonal antibodies for use as blood grouping reagents ${ }^{[4]}$. The agglutination reaction was achieved using one volume of the antibody solution and one volume of the red cells in suspension at $2 \%$. Macroscopic readings were taken after $1 \mathrm{hr}$ of incubation at RT followed by centrifugation for $1 \mathrm{~min}$ at $1000 \mathrm{rpm}$. The intensity was expressed using the following nomenclature: $(+4)$ one granule and clear supernatant; $(+3)$ several granules and clear supernatant; (+2) several small granules and turbid supernatant; $(+1)$ fine granules and turbid supernatant; (+/-) very fine agglutination; (-) no agglutination ${ }^{[7]}$.

Table 2. Specificity of the 3D5D7G2 monoclonal antibody by tube hemagglutination assays

\begin{tabular}{llllll}
\hline Blood cell & No. of samples & IAT & Cold $\left(\mathbf{2 - 8} \mathbf{8}^{\circ} \mathbf{C}\right)$ & RT & $\mathbf{3 7}^{\circ} \mathbf{C}$ \\
\hline $\mathrm{A}$ & 810 & $-\mathrm{Ve}$ & $-\mathrm{Ve}$ & $-\mathrm{Ve}$ & $-\mathrm{Ve}$ \\
$\mathrm{B}$ & 880 & $+\mathrm{Ve}$ & $+\mathrm{Ve}$ & $+\mathrm{Ve}$ & $+\mathrm{Ve}$ \\
$\mathrm{O}$ & 810 & $-\mathrm{Ve}$ & $-\mathrm{Ve}$ & $-\mathrm{Ve}$ & $-\mathrm{Ve}$ \\
\hline
\end{tabular}


The specificity of each hybridoma supernatant was determined by its agglutinating capacity against a panel of red blood cells of the ABO groups. The assay was performed in Tube agglutination test by placing $30 \mu \mathrm{L}$ of undiluted supernatant $\&$ mixed with $30 \mu \mathrm{L}$ of a $2 \%$ suspension of washed red cells. The tubes were allowed to stand for an hour at room temperature (RT) and centrifuged at $1000 \mathrm{rpm}$ for one minute, then observed for agglutination macroscopically as well microscopically.

In order to determine the immunoglobulin concentration in culture supernatants by ELISA was performed twice. The correlation between the OD determined by ELISA, the Immunoglobulin quantity was calculated by a logarithmic curve plotted $(\mathrm{Y}=\mathrm{A}+\mathrm{B} \log \mathrm{X})$ in between the OD Vs. the dilutions (Figure 1) and the mean of content of association between the OD and the titer of antibody were found $172 \mu \mathrm{g} / \mathrm{ML}$.

\section{Anti-B日SA}

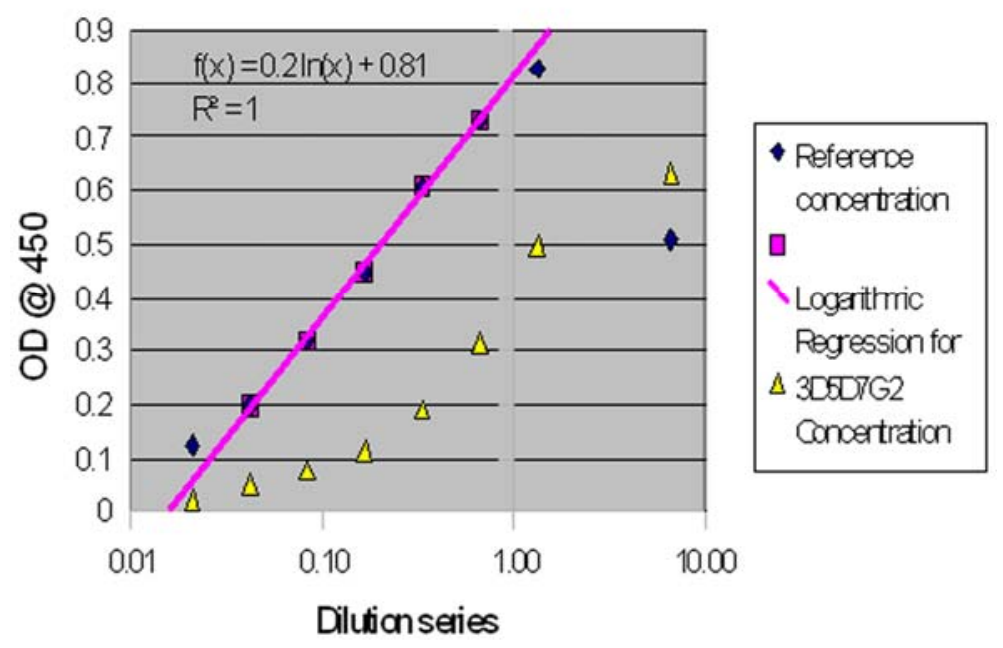

Figure 1. Anti-B ELISA with monoclonal antibody on an immunoplate coated by anti-human IgM antibody

The data point (I) have been obtained by first incubating the plates with the dilution series of reference anti-B antibody to an Anti-human IgM antibody captured by coating. In a second step conjugated anti-mouse IgM was used to reveal the content of Ig of reference anti-B antibody. The data points (II) have been obtained by incubating the plates with the dilutions as above but the anti-B monoclonal antibody and the next steps turn was made visible by conjugated goat anti-mouse IgM.

To ensure the specificity of the reagent the agglutinating system of anti-B antibody (3D5D7G2) and B erythrocytes was inhibited by the B-substance, while no inhibition was observed with the saliva of $\mathrm{O}$, A secretor subjects or with the saliva of non-secretors. It is worth noting that no differences were found in the amount of B substance needed to inhibit group B and subgroups A, B and A2B. (Data not shown)

Table 3. Stability studies of the 3D5D7G2 monoclonal antibody at different storage temperatures

\begin{tabular}{|c|c|c|c|c|c|c|c|c|c|c|}
\hline \multirow[t]{3}{*}{$2 \%$ Blood cell } & \multicolumn{6}{|c|}{ Avidity (in seconds) } & \multirow[t]{2}{*}{ Intensity } & \multicolumn{3}{|l|}{ Titer } \\
\hline & $2-8^{\circ} \mathrm{C}$ & & $37^{\circ} \mathrm{C}$ & & $45^{\circ} \mathrm{C}$ & & & & & \\
\hline & $\begin{array}{l}\text { Whole } \\
\text { blood }\end{array}$ & $10 \%$ cell & $\begin{array}{l}\text { Whole } \\
\text { blood }\end{array}$ & $10 \%$ cell & $\begin{array}{l}\text { Whole } \\
\text { blood }\end{array}$ & $10 \%$ cell & & $2-8^{\circ} \mathrm{C}$ & $37^{\circ} \mathrm{C}$ & $45^{\circ} \mathrm{C}$ \\
\hline B group & 3.3 & 3.5 & 3.5 & 3.6 & 3.6 & 3.7 & $4+$ & 256 & 256 & 256 \\
\hline AB group & 3.5 & 3.7 & 3.4 & 3.7 & 3.9 & 4.2 & $2+$ & 128 & 128 & 128 \\
\hline
\end{tabular}


The immunoglobulin class of the culture supernatant was confirmed as IgM by isotyping ELISA kit (Sigma). Table-3 shows the stability studies of 3D5D7G2 monoclonal antibody which was checked and confirmed with panel of B \& AB group erythrocytes by saline method at $2^{\circ} \mathrm{C}-8^{\circ} \mathrm{C}, 37^{\circ} \mathrm{C}$ and $45^{\circ} \mathrm{C}$.

The stability studies of culture supernatant of the anti-B 3D5D7G2 antibodies were determined by means of potency and avidity tests. The effect of different shelf storage temperature conditions was also studied on the final formulation of the anti-B reagent in $2 \% \mathrm{BSA}$ and analyzing its stability at $2^{\circ} \mathrm{C}-8^{\circ} \mathrm{C}, 37^{\circ} \mathrm{C}$ and $45^{\circ} \mathrm{C}$. Each one of the tests mentioned was carried out on first and seventh day, and the titer, avidity, and intensity were assessed by hem agglutination of standard pooled B and AB positive blood samples.

To determine the reliability of the monoclonal reagent, it was tested in parallel with the commercial reagent currently used in blood banks (Span diagnostics Ltd., Ortho's blood grouping reagents), by hemagglutination, in tube test. The results are summarized in Table 4. First, the prepared reagent was $100 \%$ specific over 2500 samples analyzed by tube hemagglutination. Second, from 880 samples of the B group, 99.7\% agglutinated with an intensity ranging from +3 to +4 ( $0.94 \%$ and $98.8 \%$, respectively) similar to the commercial Span's reagents currently in use, which gave values of $99.9 \%$ ( $0.23 \%$ and $99.7 \%$, respectively).

Table 4. Performance of the anti-B reagent by tube hemagglutination assays

\begin{tabular}{|c|c|c|c|c|c|c|c|c|c|}
\hline & & & & Tub & & & & & \\
\hline & Span commerci & agen & & & & & l rea & & \\
\hline & & Inte & & & & Int & & & \\
\hline Red cells & No. of samples & +1 & +2 & +3 & +4 & +1 & +2 & +3 & +4 \\
\hline A & 810 & 0 & 0 & 0 & 0 & 0 & 0 & 0 & 0 \\
\hline B & 850 & 0 & 0 & 2 & 848 & 0 & 2 & 8 & 840 \\
\hline $\mathrm{O}$ & 810 & 0 & 0 & 0 & 0 & 0 & 0 & 0 & 0 \\
\hline$A_{1} B$ & 15 & 0 & 0 & 0 & 15 & 0 & 0 & 2 & 13 \\
\hline $\mathrm{A}_{2} \mathrm{~B}$ & 14 & 0 & 0 & 0 & 14 & 0 & 0 & 0 & 14 \\
\hline
\end{tabular}

Tests were performed in parallel with commercial reagent (Span Diagnostics Ltd. and Ortho's blood grouping reagents) by tube techniques at room temperature with an incubation period of $1 \mathrm{hr}$.

With the discovery of hybridoma technology by Kohler and Milstein there are large number of reports regarding blood grouping monoclonals for diagnostic use are available from western countries. However there are none in the Indian scenario which will cater to the needs of the Asian population. To circumvent this limitation with respect to its epitope representation and cost effectiveness we have indigenously generated B blood group monoclonal antibody catering to our needs.

The production cost ${ }^{[12]}$ of indigenously generated anti-B monoclonal antibody was Rs. 50/10 mL as compared to commercial Antisera at Rs. 250/10 mL. The cost included only the production of antibody from the thawing of hybrid cell lines on day one to the expansion in roller bottles up to day 14 . With these proportions, $10 \mathrm{~mL}$ of indigenously produced anti-B reagent in India will be 5 times economical as compared to commercial reagents. Hence, the monoclonal antibody produced by us, can be regularly used in the laboratory as a standard blood grouping reagent, ensuring a constant supply which will ultimately be cost-effective.

In our study Anti-B antibody was produced by the same method, earlier reported by Sacks \& Lennox, 1981; Iyer et al. 2006. This antibody was obtained by immunizing mice with B group erythrocytes ${ }^{[4-8]}$ and mice had been pre-bleeded before immunization to check the naturally occurring anti-B antibody. The monoclonal antibody indigenously produced us fulfilled the criteria required for a standard blood grouping reagent, i.e., potency, specificity and avidity. The monoclonal anti-B 3D5D7G2 antibody was screened for more than 2500 blood samples and found comparable to the standard Anti-B 
monoclonal antibody reagents like Span diagnostics Ltd. and Ortho's blood grouping reagent. In contrast, anti-B (3D5D7G2) antibody agglutinates B3 red cells and Bx red cells which are the weaker variant of B group.

The clone was stable, and able to secrete antibody with the same specificity even after several passages and the antibody secretion of defined specificity also confirms at different storage temperatures. The strong specific inhibition observed by adding the B-substance conforms the specificity of the MAb, indicating that it reacts with the immunodominant region of the antigen that confers the specificity to this group.

\section{Conclusion}

We generated indigenously three clones expressing anti-B specificity. However, only one of the three clones further expanded, sub cloned and 3D5D7G2 was found to be potent to be used as a monoclonal anti-B blood grouping reagent. There are number of laboratories have produced ABO specific hybridomas as a typing reagents has so far been recommended as a standard reagent ${ }^{[11,13-15]}$. The monoclonal antibody produced by us, can be used in the scale up system as a standard blood grouping reagent ensures constant supply with cost effectiveness if produced commercially.

\section{Authors' contributions}

AA conceived the study, carried out the planning and experiments and drafted the manuscript. NG carried out the immunizations, sub-cloning and testing, PP carried out the testing with blood samples for specificity, titer determination and stability studies. YI and MT guided coordinate and helped out to design and draft the manuscript. All authors read and approved the final manuscript.

\section{Acknowledgment}

We wish to thank Dr Pradip K. Desai, Founder \& Mentor Director of Span Diagnostics Ltd. for his constant support, encouragement. We are grateful to Dr S.C. Gupte, Director of Surat Raktadan Kendra \& Research Center, Surat for evaluating the suitability of this clone as a blood group reagent. We are thankful to our quality control department for providing blood samples and testing of the reagent.

\section{Conflict of interest}

The author(s) declare that they have no competing interests.

\section{References}

[1] Landsteiner K, Über Agglutinationserscheinungen normalen menschlichen Blutes. Wien. Klin. Woschr 1901;14:1132-34.

[2] Kohler G, \& Milstein C, Continuous culture of fused cells secreting antibody of predefined specificity. Nature 1975;256:495-97. http://dx.doi.org/10.1038/256495a0

[3] Barnstable CJ, Bodner WF, Brown G, Galfre G, Milstbin C, et al. A: Production of monoclonal antibodies to group A erythrocytes, HLA and other human cell surface antigens-new tools for genetic analysis. Cell 1978;14:9-20. http://dx.doi.org/10.1016/0092-8674(78)90296-9

[4] Voak D, Lennox E, Sacks S, Milstein C, \& Darnborough J, Monoclonal anti-A and anti-B: Development as cost effective reagents. Med Lab Sic 1982;39:109-22.

[5] Fletcher A, Harbour C \& De Zwart R, Monoclonal antibodies specific for blood groups A and B. Aust. J. Exp. Biol. Med. Sci. 1984;62:421-28. PMid:6517763 http://dx.doi.org/10.1038/icb.1984.40

[6] Iyer YS, Vasantha K, Manisha P, Jadhav S, Gupte SC et al. Production of murine monoclonal anti-B. Indian J Med Res.2006;123:561-64. PMid:16783048

[7] Becker MI, Juica F, Jamett A, Tzichinovsky S, Barros S, et al, Development of Anti-Human B blood group monoclonal antibodies Suitable as a blood typing reagent. HYBRIDOMA 1994;13(4):303-10. PMid:7806251 
[8] Bundle D, Gidney MAJ, Kassam N, \& Rahman AFR, Hybridomas specific for carbohydrates; synthetic human blood group antigens for the production, selection, and characterization of monoclonal typing reagents. J Immunol 1982;129:678-82. PMid:6177774

[9] Barrie EK, Fraser RH, Munro AC, Williamson AR, Hamilton EA et al. Monoclonal anti-B produced by the immunization of mice with soluble salivary glycoproteins. J Immunogen 1983;10:41-44.

[10] Rouger PH., Edelman L, Dionel CH, Reviron J, Salmon CH et al, Study of blood group B antigen with a specific monoclonal antibody (anti-B, b-183). Immunology. 1983;49:77-82. PMid:6840810

[11] Bhatia HM, Procedures in Blood Banking and Immuno-hematology, Blood Group Reference Centre and Indian Council of Medical Research, New Delhi;1977.

[12] Tod A, Chirnside A. Monoclonal antibody production: A cost comparison. Med Lab Sci 1988;45:161-64. PMid:3210922

[13] Okubo Y, Reactivity of monoclonal antibodies as blood grouping reagents. Nippon Kinsho. 1997;55:2340-46.

[14] Strobel E, Suitability of monoclonal reagents in determination of ABO blood groups of newborn infants. Infusionsther Transfusionmed. 1996; 23:138-42. PMid:8924749

[15] Sacks SH, \& Lennox ES, Monoclonal anti-B as a new blood typing reagent. Vox Sang 1981;40:99-104. PMid:6785927 http://dx.doi.org/10.1111/j.1423-0410.1981.tb00677.x 